\title{
IMPÉRIO, ESTADO E IDEOLOGIA NA URSS STALINISTA*
}

Silvio Pons

Em seu trabalho dedicado ao Império Russo, Dominic Lieven enfatiza a exigência de "colocar a história da Rússia em seu contexto internacional”, na crença de que, mais do que qualquer outro fator, os desafios da política de potência "foram de preponderante importância na história russa”, compreendido o período soviético. O lugar da Rússia na "mutável constelação européia e global do poder" aparece assim como o núcleo central de uma reconstrução voltada para colocar o próprio episódio da União Soviética no quadro da ascensão e da queda de uma potência imperial na presença dos seus "rivais", resolvendo com essa chave o problema histórico da continuidade com o passado czarista (Lieven, 2000). O estudo de Lieven contribuiu, entre outras coisas, para introduzir a noção de "império soviético", usada antes de 1991 de forma esporádica e freqüentemente rejeitada por meros motivos políticos, no debate histórico que nos anos mais recentes apresenta um interesse renovado em torno do tema do império. A apro-

* Tradução de Arlete Dialetachi. 
ximação que daí deriva parece muito viva e destinada a influenciar de forma significativa a historiografia, embora tal interesse seja suscitado muito menos por uma reflexão sobre o fim da União Soviética e muito mais pelos questionamentos e debates sobre o papel mundial desempenhado pelos Estados Unidos. O deslizamento da "sociedade civil" ao "império" no discurso público do nosso tempo, apontado por Charles Maier, reflete a vantagem daquela prioridade política e intelectual (Maier, 2006). Se, porém, não se descarta o fato de que a noção de império impõe sua centralidade no que diz respeito aos Estados Unidos, ela certamente não poderá ser ignorada nas futuras análises sobre a ascensão e a queda da União Soviética e do comunismo.

A gênese da estrutura imperial soviética faz parte da própria história da revolução bolchevique e da guerra civil russa. A parcial reconquista dos territórios perten100 centes à conexão czarista entre a desagregação dos Impérios centrais e a guerra polaco-soviética foi a premissa para a constituição do Império "interno". Mas a noção de império assume o seu significado definitivo somente na era stalinista. Sob um duplo perfil. Em primeiro lugar, o da máxima centralização da estrutura estatal por meio da combinação entre russificação, repressão e isolamento. Em segundo lugar, o da constituição do império "externo" na Europa central e oriental após a Segunda Guerra Mundial e da Guerra Fria com os Estados Unidos. À luz dos arquivos, as dinâmicas de ambos esses processos sãonos hoje muito mais claras do que no passado. Em particular, é agora possível compreender bem melhor o nexo entre contexto interno e contexto externo. O clássico dilema imperial da segurança das fronteiras parece decisivo para explicar a natureza nacional, e não apenas social, das repressões stalinistas na segunda metade da década de trinta. Assim como a relação entre expansão e seguran- 
ça estava na origem dos primeiros e brutais experimentos de sovietização consumados no dia seguinte ao pacto Molotov - Ribbentrop. Esse problema, que na mentalidade soviética apresentava um enredo de natureza policial, geopolítica e ideológica, permanecia sem solução ao final da Segunda Guerra Mundial, sinalizando claramente primeiro a planificação dos acordos europeus do pós-guerra e em seguida a sua concreta realização no "cordão sanitário" abatido (Bettanin, 2006).

Muito aproximativos são, porém, os nossos conhecimentos concernentes aos processos de decisão e às estratégias que sustentaram a ascensão da potência soviética sob a liderança de Stalin, para constituir um legado irremovível quase até o fim. Lamentar as limitações de nosso acesso à decision making stalinista já se tornou, entretanto, um lugar comum, e provavelmente ainda o será por muito tempo. Muitos documentos de arquivo permanecem fora do alcance dos investigadores, a começar por uma parte essencial das cartas pessoais de Stalin. Nesse meio tempo, políticaspraxe que se instauraram na época, tais como a fragmentação das sedes de decisão, a desautorização do Politburo, a tradição de decidir os assuntos de Estado na casa de campo particular de Stalin, nos levam a deduzir que dificilmente encontraremos respostas para numerosas perguntas. $\mathrm{O}$ fato, porém, é que insistir na decision making pode ser um equívoco, pois o problema parece ser mais amplo: ele é resultado da dificuldade de se obter uma síntese interpretativa e um consenso historiográfico em torno das motivações profundas da política e da perspectiva imperial, dos elementos culturais e ideológicos que tinham prioridade nas estratégias de Stalin, das motivações e dos objetivos dessas mesmas estratégias. Basta pensar no "paradigma revolucionário-imperial” adotado por Vladislav Zubok e Constantine Pleshakov, provavelmente a tentativa mais equilibrada de fornecer uma leitura dos diversos componentes da política 
de potência de Stalin. Essa fórmula apresenta uma eficácia descritiva, colocando na base do pensamento de Stalin até nos anos vinte

"a promessa do universalismo revolucionário comunista combinada com a necessidade de sobrevivência para a União Soviética, o primeiro e único 'império socialista"” (Zubok, 1996, pp. 12-19, 74).

Mas a justaposição dos dois termos é indicativa de uma incerteza analítica, uma pergunta não respondida sobre a autêntica supremacia de um ou do outro nos diversos momentos históricos. A que se segue é uma reflexão sobre essa encruzilhada histórica.

As ações políticas de Stalin eram claramente condicionadas por um corpus de princípios axiomáticos. Esses princípios haviam sido irreversivelmente plasmados pela 102 doutrina de Lenin sobre o imperialismo e pelas respostas dos bolcheviques aos eventos internos e internacionais de 1918-1920. Sobre a base da concepção leninista e da concreta experiência consumada na revolução e na guerra civil, os bolcheviques se consideravam protagonistas de uma época de revoltas e guerras. A visão que eles tinham da guerra civil internacional ditou o imperativo de adotar uma estratégia de sobrevivência para a Rússia revolucionária, essencial para manter vivo o projeto de "revolução mundial" que os havia orientado de 1917 em diante, embora com uma intensidade cada vez menor. Stalin se fez intérprete daquela visão e daquele imperativo em meados da década de vinte, quando se impunha tomar providências para pôr fim à época revolucionária na Europa. Ele não se limitou a executar exatamente o ensinamento leninista exemplificado sobre a paz de Brest, a idéia de que a tarefa essencial do poder soviético fosse desfrutar das "contradições" entre as potências imperialistas para garantir a própria segurança (De Biagio, 
2004). A existência de um "Estado de paz armada" entre "o mundo do capitalismo e o mundo dos Sovietes" apresentava para Stalin também um outro corolário: a incumbência dos bolcheviques era "substituir a atual circunscrição capitalista por uma socialista”, um desenho estratégico válido para toda uma época por vir (Stalin, 1946-1952, vol. VIII, p. 263). A profecia da guerra dominou a "revolução do alto" lançada no final da década de vinte. Essa obsessão adquiriu um novo vigor após a ascensão de Hitler ao poder, quando as psicoses soviéticas começaram a se confirmar pela existência de uma real ameaça de guerra na Europa (Romano, $2000)^{1}$. A resposta de Stalin à "guerra civil internacional" foi a construção da potência soviética.

Ele impôs a si mesmo três objetivos: dar seqüência ao processo de State-building ativado por Lenin até a criação daquilo que Antonio Gramsci denominava "estadolatria", a idolatria do Estado; impor a perspectiva de uma modernização forçada como exigência vital e premente à luz dos desafios da política mundial; incrementar a separação estratégica da URSS do sistema internacional no plano econômico, político, sociocultural. Tal separação não respondia simplesmente a uma técnica do poder. Ela expressava uma divisão de planos que assinalava um desenvolvimento original da cultura política soviética por meio da doutrina do "socialismo em um único país”. Em 1925 Bucharin indicou, entre os elementos essenciais daquela doutrina, a distinção entre as "formas da luta de classes" nos mundos soviético e capitalista: nas condições da ditadura do proletariado, o "partido da classe operária" se transformava no "partido da paz civil", voltado para a "edificação socialista"; mas, no contexto do sistema capitalista, o "partido da classe operária" devia permanecer como o "partido da guerra civil" forjado por Lenin. Segundo Bucha-

\footnotetext{
${ }^{1}$ Sobre a percepção difusa (generalizada) da guerra na União Soviética nos anos 1930, cf. Rossija Zapadi (1998).
} 
rin, a principal garantia da "construção pacífica" na URSS, dado o seu isolamento internacional, continuava a ser a defesa dos interesses da "revolução mundial", e, por esse motivo, os bolcheviques deviam continuar a constituir o "partido da revolução mundial" (Bucharin, 1988, p. 186). Naquele tempo, Stalin aparentemente concordava com esse esquema e ponto de vista (Stalin, 1946-1952, vol. X, p. 135).

Mais tarde, Stalin devia manter o critério dualístico de Bucharin, mas subvertendo-lhe os componentes. Irônica e tragicamente, esses componentes reverteram muito rapidamente os seus destinos: a URSS experimentou o desastre incalculável de uma segunda guerra civil, desencadeada pelo Estado contra os camponeses, que levou à adoção do terror como método de governo em tempo de paz; enquanto o discurso revolucionário relançado pelo Comintern no final da década de vinte se revelava mera retórica, útil para o auto-isolamento soviético durante o primeiro plano qüin104 qüenal, e dali a poucos anos os partidos comunistas, sob a bandeira do antifascismo, entraram pelo caminho que devia levá-los a abandonar de fato as perspectivas de insurreição nos países capitalistas avançados. A distinção entre os "dois mundos", todavia, devia ser conservada sob uma nova forma com a proclamação do "socialismo realizado". De acordo com o ponto de vista vigente na cultura política stalinista dos anos trinta, o Estado socialista se baseava no fim das divisões de classes e na "unidade política e moral" da sociedade, enquanto os estados capitalistas continuavam a agir sob o impulso dos mais brutais "interesses de classe". Seja a representação "pacificada" do mundo soviético, seja aquela bélica do mundo capitalista, respondiam à lógica de se legitimar o regime de Stalin. Na realidade, aquela lógica estabelecia um princípio de "unidade social" por meio do terror planejado do alto, como meio extremo para reabsorver os conflitos e as tragédias da modernização forçada; e amplificava ao máximo a tradicional agitação da ameaça externa 
como instrumento de resgate para consolidar o "Estado de segurança total" e para mobilizar a sociedade, ocultando assim a fragilidade do sistema percebida pelas próprias elites políticas. Aqui, porém, o ponto relevante é outro: o critério dos "dois mundos" idealizado por Stalin esboçava cada vez mais uma oposição baseada no Estado, em vez de em estratégias políticas a serem aplicadas a diferentes contextos. No cenário do stalinismo, a distinção entre "paz civil” e "guerra civil" havia perdido muito de seu significado, assim como a alternativa entre "razão de Estado" e internacionalismo militante(Pons, 1995).

A partir dos meados da década de trinta, a ideologia revolucionária já não motivava a política soviética. Em vez disso, foi a concepção do mundo externo herdada do bolchevismo que passou a constituir a bússola da conduta de Stalin. Sua linguagem abandonou o nexo entre guerra e revolução que havia sido essencial para o projeto bolchevique da "revolução mundial". Stalin ainda citou aquele nexo no XVII Congresso da VKP(b) em 1934; mas, em suas participações subseqüentes e depois no XVIII Congresso, em 1939, manteve-se em absoluto silêncio a esse respeito. Não se tratava apenas de uma estratégia dissimuladora no discurso público. Em uma conversa particular com Dimitrov em novembro de 1939, Stalin declarou que a indicação de Lenin, de transformar a "guerra imperialista" em "guerra civil", não se havia revelado adequada para os trabalhadores europeus na época da Primeira Guerra Mundial: a implicação óbvia era que aquela tradição política fosse ainda menos válida após o início da Segunda Guerra Mundial(Dimitrov, 2002, p. 203). No âmbito de nosso conhecimento, o único espaço que sobrou para a noção de "revolução mundial" foi a admoestação stalinista de que: "a revolução mundial como ato único é desprovida de sentido [...] as ações do Exército Vermelho também são algo correlato à revolução mundial” (Ivi, 1940, pp. 212-221). 
A separação de planos entre os mundos soviético e capitalista não tinha mais um caráter metodológico e político. Era concebida como uma separação orgânica. Aos olhos da liderança stalinista, o Estado soviético já havia assumido um aspecto que era impossível de exprimir nos termos do radicalismo marxista e do modelo da "ditadura do proletariado" adotado pelos bolcheviques. A cultura e a linguagem mais idôneas para identificar as características do novo estadismo e patriotismo podiam, em vez disso, ser indicadas na tradição eslavófila, transfigurada em uma espécie de "bolchevismo nacional" (Brandenberger, 2002). Uma tradição inventada que apresentava singulares ecos e analogias com o moderno "socialismo nacional" europeu: estender o socialismo a toda a comunidade do povo, com o objetivo de ocultar as contradições sociais; empregar o nacionalismo como fator de unidade social e como um mito mobilizante capaz de substituir os ide106 ais da transformação socialista; transferir a luta de classes da esfera social para a das relações entre as comunidades nacionais (Sternhell, 1993). Esses elementos, porém, não foram assimilados a ponto de determinar uma revisão de identidade. A defesa da herança do Estado russo, pronunciada por Stalin em 1937 e em 1938 contra todos os "inimigos do povo", decididos a destruir "a potência da União Soviética” envolvendo o país em uma guerra, não implicava uma visão da nação centralizada sobre seus caracteres históricos e culturais² ${ }^{2}$ Em 1938-1939, Stalin apresentou uma revisão instrumental da ortodoxia marxista, usando argumentos racionais à luz das relações internacionais: a consolidação do Estado soviético se justificava pela existência de um "cerco capitalista" hostil .

\footnotetext{
${ }^{2}$ Ver, a respeito, Dimitrov (2002, p. 81 - novembre 1937). RGASPI (1938, f. 558, op. 11, d. 1122, 1. 160)

${ }^{3}$ RGASPI, 1938, f. 558, op. 11, d. 1122, 11. 80, 160. I. V. Stalin, 1967, vol. 1, Stanford, p. 395.
} 
Reservado na URSS, o código classista permanecia, portanto, essencial para definir o papel e a identidade do Estado originado pela revolução na política mundial. A fonte de legitimação representada pela revolução era irrenunciável. Ela não constituía somente o evento originário da transformação socialista reivindicada pelo regime. Além disso, oferecia um inestimável elemento de força que nem o Império russo, nem outros impérios modernos haviam possuído: a possibilidade de contar com uma multidão organizada de seguidores no campo adversário. Mas, sobretudo, fornecia a constituição material da potência soviética, o núcleo principal das concepções em que se baseava a sua conduta e a sua missão. Durante a Segunda Guerra Mundial, o patriotismo e o "nacionalismo messiânico" russo emergiram como uma ideologia oficial, destinada a permanecer dominante até o final da URSS (Hosking, 2006, p. 230). Stalin, porém, se manteve impermeável à idéia de integrar o processo de State-building com um processo de Nation-building.

A mesma noção de "interesse nacional" idealizada por Stalin por ocasião da aliança com Hitler demonstrou uma transparente referência à tradição imperial russa, mas não se confinou a uma visão geopolítica: a idéia de que o colapso do sistema de Versalhes abriria novas oportunidades à potência soviética, cultivada entre 1939 e 1941, apresentava um preciso conteúdo ideológico, pois equiparava a potência alemã às ocidentais sob a categoria do imperialismo em vez de enfocar o desafio radical constituído pelo nazismo. O "hiper-realismo" de Stalin não excluía, e sim pressupunha a ideologia (Stephanson, 2001). Quando o dado central deixou de ser a queda de Versalhes e passou a ser o da "nova ordem" nazista e do Terceiro Reich, que escancarava à influência soviética o coração da Europa, os termos da questão não mudaram. Em 1944, os argumentos do historiador Tarle em favor de uma reabilitação da legítima política de potência russa foram rejeitados por Zdanov 
e seus ideólogos sob a supervisão de Stalin (Pons, 2000). Às vésperas da conferência de Ialta, a política de Stalin se voltava para a continuação, o quanto fosse possível, da colaboração com os ocidentais; mas a sua visão em longo prazo se concentrava no cenário de uma futura luta entre os soviéticos e a "facção capitalista" que fora sua aliada em guerra: a profecia de um confronto com base nas noções de classe e de Estado, não de nação (Dimitrov, 2002, p. 802).

No exato momento de expressar tal profecia, Stalin se vangloriou de haver obtido algo que nem mesmo a mente audaz de Lenin havia ousado esperar: a aliança da Rússia soviética com um grupo de capitalistas contra outro grupo de capitalistas ${ }^{4}$. Sua visão das alianças e dos conflitos com o mundo capitalista representava o corolário de uma transformação estratégica. O que realmente contava, mesmo após a vitória na Segunda Guerra Mundial, não era mais o projeto revolucionário dos bolcheviques, e sim o sucesso 108 da política de potência soviética no afrontamento e desmoronamento do "mundo" composto pelas outras potências capitalistas, começando pela inclusão de uma parte da Europa no "mundo" soviético. O crescimento da potência soviética era visto como um fim em si mesmo, que havia consentido em expandir o "socialismo" e em permanecer fiel aos ensinamentos de Lenin. Como observa Lieven com base nas memórias de Molotov, o tradicional princípio imperial que ligava território, expansão e poder vinha expresso pelos dirigentes stalinistas "com uma crueza tal que teria feito tremer até mesmo os ministros de Nicolau II" (Lieven, 2000, p. 295).

Stalin baseou sua estratégia na idéia de que a Segunda Guerra Mundial seria apenas um capítulo de uma era de catástrofe, seguindo as pegadas de Lenin na Primeira

\footnotetext{
${ }^{4}$ Cf. Vostocnaja Evropa v dokumentach rossiiskich archivov 1944-1953, tom I, Sibirskij Chronograf, Moskva, 1997, doc. 37.
} 
Guerra Mundial, mas aplicou a elas sua própria versão do esquema de divisão do mundo concebido pelos bolcheviques após a morte de Lenin, centralizada no culto da potência. Sua atenção maníaca ao vocabulário que deveria ser empregado na definição das tendências políticas internacionais no mundo pós-guerra nascia de uma experiente circunspecção, mas também de uma visão antagônica do papel da potência soviética (Naimark, 2002). Isso implicava o reconhecimento do nascimento do sistema bipolar e, portanto, o fim do principal axioma de segurança seguido no passado, o de aproveitar as "contradições" que dividiam as potências capitalistas. O sentimento de insegurança que dele derivava impediu, por muito tempo, o emergir da nova linguagem dicotômica soviética. Foi somente após o lançamento do Plano Marshall, durante a preparação da conferência de fundação do Cominform, que a tese dos "dois campos" no mundo pós-guerra foi adotada nos rascunhos do relatório de Zdanov, talvez com base em uma proposta de Molotov aprovada por Stalin (Adibekov et al., 1994). Mas a fórmula mais reveladora foi, provavelmente, a empregada no relatório de Malenkov na conferência, no qual se lia que

"desde o momento em que as classes antagônicas foram liquidadas na URSS e que a unidade política e moral da sociedade soviética foi conquistada, toda a aspereza da luta de classes para a URSS foi deslocada para a arena internacional" (Gibianskij, 1998, p. XXXVII).

O deslocamento da "luta de classes" para o exterior, no campo das relações interestatais, não fornecia uma doutrina para a "revolução mundial", que, na realidade, jamais voltou a fazer parte do discurso político da Cominform (Pons, 1999). Em vez disso, procurava enfatizar a peculiar qualidade da potência soviética, o seu papel antagônico na política 
mundial como eixo de sustentação do "campo socialista" e guia das "forças antiimperialistas", a sua rejeição do projeto hegemônico americano implícito no Plano Marshall em nome de um desafio de natureza ideológica e militar. Quando Litvinov, já em junho de 1946, confidenciou a um jornalista ocidental seu desapontamento com a restauração de uma "concepção ideológica" no coração da política externa soviética, não estava denunciando a retomada da tradição revolucionária, e sim a idéia dogmática de que seria "inevitável um conflito entre o mundo capitalista e o mundo comunista" (Ultimes paroles de Maxime Litvinov, 1952) ${ }^{5}$. Mais que em um desenho pré-ordenado, os pressupostos para a sovietização da Europa centro-oriental se encontravam naquela "concepção ideológica", em uma cultura política incapaz de conceber o exercício do poder senão como domínio e conflito permanente, no interior do Estado e nas suas relações internacionais (Naimark, 2004).

110 A "razão de Estado" stalinista removeu apenas um componente da cultura política bolchevique, a idéia da "atualidade" da revolução. As principais categorias interpretativas do mundo, geradas pelo leninismo, tiveram, ao contrário, uma longa duração e constituíram uma base rígida destinada a sofrer poucas alterações a não ser na crise final da URSS: uma combinação híbrida entre psicologia do cerco, visão catastrófica do capitalismo, expectativa da guerra, mitologia de uma modernidade alternativa. O irredutível antagonismo da visão do mundo forjada na época da revolução foi colocado na base da concepção do Estado e da sua política de potência. Essa transformação, porém, sinalizava o fim, e não a realização do "projeto revolucionário" dos bolcheviques. O acerto de contas com o capitalismo foi colocado em um futuro indefinido e confiado à profecia de novos e inevitáveis conflitos, cenário da longa marcha

${ }^{5}$ Sobre a circunstância destas afirmações de Litvinov, cf. Roberts (2002, pp. 49-50). 
do comunismo mesmo após a Segunda Guerra Mundial. A influência político-militar e o domínio imperial conquistados pela URSS na guerra se tornaram uma linha de demarcação e uma trincheira a ser defendida. A utopia revolucionária originária assumiu definitivamente o aspecto de uma missão de época do Estado, alimentada pela fé na "superioridade" do sistema soviético em relação ao capitalista e pelo ethos militaresco que depositava fé no inevitável deslocamento das "relações de força" internacionais a favor do “campo socialista” e da URSS.

Foi o desafio pelo poder mundial que forneceu uma identidade não obsoleta ao Estado nascido da revolução, fundando na realidade um princípio de autoconservação. Em um sistema agora bipolar, o confronto com o "mundo" capitalista e a futura expansão do comunismo soviético eram confiados à centralização da própria esfera de influência, à militarização das relações internacionais, à separação sistêmica contra as interdependências mundiais. Foi esse o legado imperial consignado por Stalin a seus sucessores. Na época da Guerra Fria, o Estado soviético propunha um universalismo aparentemente mais expansivo e mobilizante do que o do próprio antagonista: os Estados Unidos. Mas, paradoxalmente, ele se converteu em herdeiro de uma concepção imperial com características muito mais tradicionais e destinada a sucumbir diante dos desafios de uma modernidade que era incapaz de encarar.

\section{Silvio Pons}

é professor titular da cadeira de História da Europa Oriental na Universitá di Roma II e diretor do Instituto Gramsci (Roma, Itália) 


\section{Referências bibliográficas}

ADIBEKOV, G. et al. (eds.) 1994. "The Cominform. Minutes of the three Conferences 1947/1948/1949”. Annali, XXX, Milano, co-editors Fondazione Feltrinelli.

BETTANIN, F. 2006. Stalin e l'Europa. La formazione dell'impero esterno soviético. Roma: Carocci.

BRANDENBERGER, D. 2002. National bolshevism: stalinist mass culture and the formation of modern Russian national identity, 1931-1956. Cambridge, Mass.: Harvard University Press.

BUCHARIN, N. I. 1988. Izbrannye proizvedenija. Moskva: Politizdat.

DE BIAGIO, A. 2004. Coesistenza e isolazionismo. Mosca, il Komintern e l'Europa de Versailles (1918-1928). Roma: Carocci.

DIMITROV, G. 2002. Diario. Gli anni de Mosca (1934-1945). A cura de Silvio Pons. Torino: Einaudi.

GIBIANSKIJ, L. 1998. Dolgij put'k tainam: istoriografija Kominforma. In Sovescanija Kominforma. 1947, 1948, 1949. Dokumenty $i$ materialy. Moskva: Rosspen.

HOSKING, G. 2006. Rulers and victims. The Russians in the Soviet Union. Cambridge, Mass.: Harvard University Press, p. 230.

LIEVEN, D. 2000. Empire. The Russian empire and its rivals. London: John Murray.

LITVINOV, M. Ultimes paroles de Maxime Litvinov, 1952. Paris: BEIPI, Decembre.

MAIER, C. S. 2006. Among Empires. American ascendancy and its predecessors. Cambridge, Mass.: Harvard University Press.

NAIMARK, N. M. 2002. "Cold War studies and new archival materials on Stalin”. The Russian Review, $\mathrm{n}^{\circ}$ 61, January. . 2004. "Stalin and Europe in the postwar period. 1945-1953: issues and problems". Journal of Modern European History, vol. 2, $\mathrm{n}^{\circ} 1$. PONS, S. 1995. Stalin e la guerra inevitabile. Torino: Einaudi. . 1999. L'impossibile egemonia. L'URSS, il PCI e le origini della guerra fredda (1943-1948). Roma: Carocci.

2000. "In the aftermath of the age of wars: the impact of World War Two on Soviet Security Policy". In: ; ROMANO, A. (eds.).

Russia in the age of wars 1914-1945. Milano: Fondazione Feltrinelli, Annali, XXXIV.

RGASPI - Rossijskij Gosudarstvennyj Archiv Socil'no-Politiceskoj Istorii. 1938. Archivio statale russo per la storia política e sociale, f. 558, op. 11, d. 1.122, ll. 80, 1. 160, I, V. 
ROBERTS, G. 2002. “Litvinov's lost peace, 1941-1946”. Journal of Cold War Studies, $\mathrm{n}^{\circ} 4$, Spring.

ROMANO, A. 2000. "Permanent war scare: mobilization, militarization, and the peasant war". In: PONS, S.; ROMANO, A. (eds.). Russia in the age of wars 1914-1945. Milano: Fondazione Feltrinelli, Annali, XXXIV.

ROSSIJA; ZAPAD. Formirovanie vnesnepoliticeskich stereotipov v soznanii rossijskogo obscestva pervoj polovini XX veka. 1998. Moskva: Institut Rossijskoj Istorii RAN.

STALIN, I. V. 1946-1952. Socinenija. Moskva, 13 volumes. 1967. Works. Stanford, vol. 1.

STEPHANSON, A. 2001. "Stalin's hyper-realism". Diplomatic History, n ${ }^{\circ}$ 25, Winter.

STERNHELL, Z. 1993. Nascita dell'ideologia fascista. Milano: Baldini \& Castoldi,

VOSTOCNAJA Evropa v dokumentach rossiiskich archivov 1944-1953. 1957. Moskva: Sibirskij Chronograf, tomo I, doc. 37.

ZUBOK, V. C. P. 1996. Inside the Kremlin's Cold War. From Stalin to Khrushchev. Cambridge, Mass.: Harvard University Press. 


\section{IMPÉRIO, ESTADO E IDEOLOGIA NA URSS STALINISTA}

SILVIO PONS

Muito aproximativos são os atuais conhecimentos sobre os processos de decisão e as estratégias que sustentaram a 
ascensão da potência soviética sob a liderança de Stalin, um legado irremovível quase até o fim. Vários documentos de arquivo permanecem fora do alcance dos investigadores, a começar por uma parte essencial das cartas pessoais de Stalin. Contudo, insistir na decision making pode ser um equívoco, pois o problema parece ser mais amplo: ele é resultado da dificuldade de se obter uma síntese interpretativa e um consenso historiográfico em torno das motivações profundas da política e da perspectiva imperial, dos elementos culturais e ideológicos que tinham prioridade nas estratégias de Stalin, das motivações e dos objetivos dessas mesmas estratégias. O presente artigo faz uma reflexão em torno dessa dificuldade.

Palavras-chave: Império soviético; Estado soviético; Stalin e stalinismo; Ideologia.

\section{EMIPIRE, STATE AND IDEOLOGY IN STALINIST USSR}

Too much aproximate indeed is the present understanding of the decision-making processes and strategies that gave support to the rise of the Soviet power under the leadership of Stalin, an insurmountable legacy almost to the end. Many archive sources are still out of reach, an essential part of Stalin's personal letters to begin with. However, to insist on decision making may be a mistake, because the problem seems wider: the difficulty of achieving an interpretative synthesis and historiographical consensus about the deep motivations underlying the imperial perspective and policies, the cultural and ideological elements of Stalin's strategies and their own motivations and objectives. This article is a reflection on that difficulty.

Keywords: The Soviet empire; The Soviet State; Stalin and stalinism; Ideology. 